\title{
Roger Bastide e a sociologia francesa: traição ou tradução do sagrado?
}

Dora Vianna Vasconcellos ${ }^{1}$

Resumo: $\mathrm{O}$ artigo pretende identificar o que foi talvez uma busca de filiação ao reconstruir o diálogo de Roger Bastide com a sociologia francesa. Na obra do intelectual há referência a autores divergentes, o que torna difícil saber se de fato Roger Bastide fez uma escolha teórica. Diante de tal dificuldade, resta apenas identificar os letimotifs ou a linha de força por meio da qual tantas orientações teóricas se congregam. É com esse intuito que se retomará a perspectiva aberta por Émile Durkheim, Marcel Mauss, Maurice Halbwachs e Georges Gurvitch, autor que, embora não fosse francês de origem, sofreu influência desta tradição sociológica, sendo constantemente reverenciado por Bastide.

Palavras-chaves: sociologia; sociologia francesa; Roger Bastide.

\section{ROGER BASTIDE AND THE FRENCH SOCIOLOGY: BETRAYAL OR TRANSLATION OF THE SACRED?}

Abstract: In an attempt to identify what might have been an affiliation, the article reconstructs the dialogue between Roger Bastide and the french sociological tradition. It must be noticed that the work of the author is revealed through introspections that make difficult to know if Roger Bastide in fact made a theoretical choice. Facing this difficulty all we can do is to identify the leitmotifs or the power line

\footnotetext{
1 Programa de Pós-Graduação de Ciências Sociais em Desenvolvimento, Agricultura e Sociedade (CPDA) da Universidade Federal Rural do Rio de Janeiro (UFRRJ) - Rio de Janeiro - Brasil - doravianna.vasconcellos3@gmail.com
} 
that congregated so many divergent theoretical orientations. For this purpose we will return to the perspective introduced by Émile Durkheim, Marcel Mauss, Maurice Halbwachs and George Gurvith, who in spite of not being originally french, suffered the influence of this intelectual tradition and was constantly worshipped by Bastide.

Keywords: Sociology; French Sociology; Roger Bastide.

\section{Introdução}

Ao longo de sua trajetória, Roger Bastide reverenciou os mais variados aportes teóricos. Foi tido, por isso, como um autor demasiadamente eclético, que muitas vezes sacrificou a densidade teórica de seus estudos na intenção de descrever a complexidade do real. A amplitude de seus questionamentos o permitiu enveredar por cearas até então não exploradas pela sociologia, como as que são dadas pelos fatos do inconsciente, do sonho, do imaginário, das artes e da literatura. Por esta razão, muitas de suas indagações se apresentam como respostas de um intelectual que almejava, antes de tudo, a erudição, e para quem a especialização acadêmica em disciplinas sempre foi pouco sedutora, afeito que era às introspecções. A inquietude diante dos mistérios da vida em sociedade sempre o levou a ficar numa posição limítrofe entre o ensaio e a escrita acadêmica, ainda que suas obras exaltem os rigores metodológicos da sociologia e da antropologia. Em meio às suas digressões, esse artigo busca identificar os letimotifs que levaram o autor a se filiar à tradição sociológica fundada por Durkheim, ainda que tenha direcionado a ela duras críticas.

Pode-se dizer, com os erros que toda generalização introduz, que à época em que Bastide iniciou seus estudos, a sociologia francesa elegia a relação entre indivíduo e sociedade como a questão principal dos estudos sociológicos. Ansiava-se saber qual era o grau de autonomia que os indivíduos possuem frente a forças coercivas coletivas e sociais. A tradição Durkheimiana asseverava a preponderância do social sobre o individual como condição para que a vida em sociedade fosse possível. Daí o sagrado em Durkheim ser dado pela força das representações coletivas e o profano por tudo que está ligado ao cotidiano e à esfera individual. Bastide, insurgindo-se contra essa perspectiva, considerou que o indivíduo não era fonte do irracional e da desordem, pois também o sagrado comportaria o livre-arbítrio, a escolha.

Bastide, assim como Durkheim, ocupou-se dos estudos de religião, mas requalificou a dimensão do sagrado ao interpretar a relação entre indivíduo 
e sociedade de um novo modo. Em sua obra sobre as religiões africanas no Brasil, o autor comprovou que mesmo o indivíduo que se encontra no nível mais baixo da hierarquia social raciocina pelas leis das contiguidades e das diferenças, tendo possibilidade de escolha e de discordância em relação aos valores religiosos dominantes. Observou que este fora um importante mecanismo de luta contra a escravidão porque permitiu que a camada dominada formasse uma autorrepresentação independente da camada senhorial. Teria sido por esta razão que acervos culturais africano, indígena e euro-ibérico não se misturaram numa síntese, mas se justapuseram, fazendo da cultura brasileira uma composição em mosaico.

Deste modo, em seus estudos sobre religiões africanas no Brasil, a antiga indagação sobre saber se o indivíduo goza de autonomia em relação à razão coletiva é repensada de acordo com os desníveis econômicos e sociais do país. Ao que tudo indica, Bastide adotou alguns dos aportes teóricos do marxismo, ainda que tenha se mantido crítico a esta tradição intelectual. Daí viria a sua discordância em relação à algumas interpretações da escola sociológica francesa.

Todavia, ainda que tenha requalificado a dimensão do sagrado, deixando em evidência sua dissidência em relação à escola durkheimiana, cumpre assinalar que tal posicionamento não marca uma total ruptura com essa escola. Para que se evidencie o sentido da crítica operada pelo autor a essa tradição intelectual, é necessário retomar algumas das questões que guiaram a sociologia francesa e algumas das ressignificações propostas por Bastide, principalmente após eleger as religiões africanas no Brasil como objeto de seus estudos. Resta saber se o intelectual, ao supor que o indivíduo não é fonte do irracional e da desordem, negou de fato o poder sagrado atribuído às representações coletivas ou à moral social que promove uma aliança entre as partes e o todo, interpretação que norteou a tradição intelectual francesa e que a impediu de reconhecer a existência de uma dimensão dialética entre indivíduo e sociedade.

Bastide enriqueceu a tradição sociológica durkheimiana com os aportes teóricos trazidos por Marcel Mauss e Maurice Halbwachs, autores que direcionaram algumas críticas à esta teoria, embora também compactuassem da ideia de que apenas a moral social que suscita uma coesão entre as partes e o todo é capaz de acoimar os vícios da sociedade capitalista. No artigo, faz-se referência também a Georges Gurvicth, autor que, muito embora não fosse francês, também se deixou influenciar pelo pensamento de Durkheim, para que se evidencie o real sentido da crítica operada por Bastide. Longe de ter sido um autor dissidente, Bastide, assim como Gurvitch, incorporou a dimensão estrutural em 
seus estudos, mas para fazer sobressair nela o sentido organizacional, fazendo jus ao legado deixado por Durkheim.

\section{Tentativa de filiação teórica}

Roger Bastide reverenciou, a longo de toda a sua obra, diferentes tradições intelectuais, além da sociologia francesa. No entanto, interessa ressaltar o que foi talvez uma titubeante filiação: a predominância em seu pensamento dos aportes teórico herdados da sociologia francesa. Nas suas obras de juventude, tal adesão se estabeleceu pela crítica, enquanto que, nas suas obras de maturidade, houve uma aproximação mais efetiva do autor em relação ao ponto de vista inaugurado por Durkheim. Essa aproximação se deu por meio da sociologia de Mauss, Halbwachs e de Gurvitch. É que Bastide também enalteceu a liberdade individual que é apaziguada pelo livre curso social, ainda que, em seus primeiros trabalhos, o intelectual tenha sido crítico à ênfase coletivista de Durkheim, que identificava o sagrado ao fato coletivo.

Em suas obras iniciais, Bastide sublinhou a importância dos fatores individuais para a compreensão dos fenômenos religiosos. Ao mesmo tempo, fez uma crítica à Durkheim ao refutar a ideia de que o fato social deva ser tratado como coisa, ou seja, como sendo exterior ao sujeito. Enquanto Durkheim se manifestava contrário à qualquer tipo de introspecção e identificava o individual ao irracional e ao profano, Bastide considerava um erro o desejo de eliminar o individual da análise sociológica ou fazer do sentimento religioso e do sagrado um sentimento exclusivamente social. E, assim, ele se aproxima de uma tradição intelectual dissidente ao propor uma análise da sociedade com ênfase nas manifestações individuais (Peixoto, 2000). ${ }^{2}$

$\mathrm{O}$ autor notara que o indivíduo possui um poder de interferência sobre os fatos sociais ao perceber que a crença religiosa é reflexo também de uma convicção pessoal. Reconhece, então, na atuação individual um elemento modificador dos procedimentos sociais. Daí as ideias religiosas poderem interferir de forma decisiva nos contornos da morfologia social. ${ }^{3}$

Tal ponto de vista teria sido reafirmado nos estudos de Bastide sobre as religiões animistas-fetichistas do Brasil quando ele descobre a existência do princípio de cisão e participação na mentalidade do escravo. Segundo ele, tal

\footnotetext{
2 Refiro-me a Gaston Richard e Gabriel Tarde. Este último considerou que as ciências da sociedade deveriam tomar o indivíduo como predestinado à vida social e ter como base o estudo da alma humana. Bastide, no início de sua trajetória, também se interessou pelas obras de Andre Gide (Peixoto, op cit).

3 Bastide chega a esta mesma conclusão ao observar a relação entre arte e a vida social (Queiroz, 1993).
} 
princípio impediu que o homem cativo se tornasse um homem marginal dividido entre duas culturas opostas: a africana, que tinha um matiz comunitário, $\mathrm{e}$ a ocidental, de orientação capitalista. E assim estes dois mundos coexistiam na sua cabeça, embora fossem distintos, senão opostos. ${ }^{4} \mathrm{E}$ mais: ele descobrira que foi por meio da agência individual que os escravos originaram verdadeiras comunidades de auxílio-mútuo que tinham como referência o ideal de reciprocidade de favores, orientação que, apesar de se basear em princípios comunitários africanos, não entrava em contradição com os valores capitalistas da sociedade. Deste modo, o princípio de cisão e de participação permitiram ao homem cativo resguardar as práticas comunitárias africanas, convertendo os valores do panteão africano nos termos religiosos católicos. Teria sido desta maneira que o escravo combateu a opressão econômica e cultural que sofria (Bastide, 1960). Segundo Bastide, seria justamente por permitir a transcendência em relação ao meio social opressivo que a religião animista fetichista do escravo apresentava um caráter sagrado.

É importante notar que, em seus estudos mais recentes, a interpretação do sagrado como uma força que permite a transcendência em relação ao social ganhou contornos mais nítidos. Bastide evidencia que, na realidade, usava uma acepção de sagrado muito próxima da de Durkheim, ou seja, de algo que funda o social ao domesticar o indivíduo, as forças da desordem. Bastide interpreta o candomblé como uma religião porque não faz referência às diferentes posições ocupadas pelos indivíduos na hierarquia social, mas às representações coletivas. O candomblé seria, portanto, a emanação do sagrado que se institucionaliza. Ou seja, mesmo no candomblé Bastide notara que o indivíduo em transe tem seus gestos estereotipados pelas normas sociais.

Bastide não deixou de perceber, entretanto, que, com as transformações da morfologia social brasileira, as religiões africanas estavam se convertendo em magia, ou seja, estavam deixando de transcender os fatos da morfologia social para refleti-los. Afinal, os ex-escravos começaram a converter os valores capitalistas nos termos dos valores comunitários africanos. Foi assim que o candomblé, no Brasil, foi paulatinamente se convertendo em macumba, seita na qual o transe se torna um improviso, evidenciando um conteúdo cada vez mais individual.

4 Por meio do princípio da cisão e da participação, Bastide chegou a conclusão, em seu estudos sobre sincretismo, que a cultura brasileira formava uma cultura em mosaico, ou seja, as diferentes orientações que a compunham não se fundiam numa síntese (Bastide, 1979). 
Ao contrário do candomblé, o transe na macumba é selvagem. O controle sobre o indivíduo é relaxado. Por isso, a macumba se institui como uma contracultura, uma força anti-sociedade. Isto é, a macumba marcou a passagem do sagrado domesticado para o sagrado selvagem, desrecalcado. Não à toa, é a macumba, e não o candomblé, que cumpre uma função catártica por permitir ao subproletariado uma maneira de expressar as contradições socioeconômicas existentes na sociedade brasileira e o seu desejo por uma outra sociedade, mesmo que seja por meio de gritos inarticulados.

Para Bastide, a macumba marcou a crise das instituições religiosas e uma anomia social. Todavia, à medida que o ex-escravo se insere na sociedade, assimila os valores capitalistas, domesticando os valores animistas-fetichistas. Os valores mágicos da macumba se converteram no espiritismo da umbanda, religião que dava novamente um caráter instituinte ao sagrado por reativar novamente o controle do social sobre o indivíduo, sendo, por isso, uma crença mais amplamente aceita pela sociedade brasileira (Bastide, 2006). Por ser uma crença amplamente aceita pela classe média, a umbanda atuaria como uma força de domesticação do sagrado selvagem da macumba, das forças que se emanam do desmedido e despertam inovações perigosas.

Importa saber que, com a adoção de uma noção de sagrado instituinte, Bastide endossa o ideal aliançista presente na sociologia de Durkheim e de seus discípulos. O espiritismo da umbanda, assim como o candomblé, são religiões exaltadas por Bastide porque permitem a conversão da lógica do do ut des africana nos termos dos valores capitalistas euroibéricos. Ao fazer com que as diferentes classes sociais compactuem entre si, o espiritismo da umbanda poderia levar, tal como acontecera com o candomblé, a uma moralização das desigualdades socioeconômicas da sociedade brasileira. Segundo Bastide, a domesticação da influência africana pelos traços ocidentais indicava um caminho suis generis para se alcançar a modernidade sem que o país incorresse nos vícios do capitalismo dos países avançados. As contradições socioeconômicas das sociedades ocidentais foram representadas por Bastide por meio do mito de Prometeu, herói sacrílego que enxerga a luz, mas tem seu fígado constantemente devorado por abutres (Bastide, 2006).

A sua concepção de sagrado instituinte se elucida quando o autor deixa transparecer a influência de Maurice Halbwachs em seu pensamento. Bastide se vale da noção de memória coletiva de Halbwachs para explicar como o acervo cultural africano se perpetuou na sociedade brasileira. Tais memórias apenas se mantiveram aqui porque reconstruíram em solo brasileiro as comunidades de auxílio mútuo que lhe deram sustentação. E assim ele chega à mesma conclusão 
que o teórico francês: as memórias coletivas estão sempre articuladas a um grupo. Mas faz um importante adendo à teoria de Halbwachs: "É a estrutura do grupo, mais do que o próprio grupo, que fornece os quadros da memória coletiva" (Queiroz, 1983 apud Bastide, 1960, p. 341-2).

Embora Halbwachs tivesse chamado atenção para a importância das estruturas sociais na conformação da mentalidade dos indivíduos, ele não estendera suas conclusões para seus estudos sobre memória coletiva. E, assim, ele permaneceu em concordância com a tradição durkheimiana, que considerava os grupos como entidades sempre permeáveis às representações coletivas. Não se atentou que o posicionamento do indivíduo ou a estrutura do grupo interferiam na formação das memórias, podendo estas estarem em discordância em relação às representações coletivas hegemônicas. Bastide marca seu afastamento em relação a Halbwachs ao assinalar a importância tanto dos indivíduos quanto das estruturas para a manutenção das recordações. Relembrando seus estudos iniciais, ele se afasta da velha escola francesa preocupada com as permanências e com a ordem ao aproximar a elaboração de Halbwachs das teorias marxistas sem que essa intenção estivesse presente no pensamento do autor (Queiroz, op cit). Foi com esta perspectiva que ele pode descrever o sagrado selvagem da macumba.

Bastide, todavia, não chega a dar às teorias de Halbwachs um outro significado por considerar que o sagrado sempre gera uma descontinuidade continuada, e não uma ruptura propriamente dita. Por ser uma força que se apoia na tradição, o sagrado se efetivaria necessariamente por meio da memória coletiva e não pelas estruturas dos grupos. Deste modo, o imaginário individual não seria nunca uma criação pura. Mesmo o sagrado selvagem da macumba seria um sagrado instituinte, um instante de ressurreição dos antigos Deuses mortos. ${ }^{5}$

É por meio dessa perspectiva que Bastide se aproximou da teoria de Georges Gurvitch, autor que, embora tenha sofrido influência do marxismo em suas análises, manteve-se crítico à essa tradição ao colocar em segundo plano o determinismo das classes para exaltar o determinismo sociológico. Tal como Marcel Mauss, pôs ênfase ao fenômeno social total que impõe a proeminência do todo sobre as partes, do coletivo sobre o individual, fazendo com que a ordenação social reflita a coletividade. Tudo indica que aproximação de Bastide de

5 Bastide afirma o sagrado como um brique-braque de antigas tradições. Renato Ortiz chamou atenção que esta interpretação está presente na obra de Bastide ao traçar um paralelo da obra de Bastide com a de Pierre Bourdieu (Ortiz, 1980). 
Gurvitch e de Mauss tenha sido a razão de sua rendição ao ideal aliancista da sociologia francesa.

Bastide chegou mesmo a reconhecer a interpretação marxista como a que está mais próxima da verdade, sobretudo quando se toma em perspectiva a história brasileira (Bastide, 1994). É que ele notara que as civilizações africanas, ao serem transplantadas para o Brasil, tornaram-se expressão ou reflexo de uma estrutura social grupal apoiada num regime de produção comunitário. A cultura comunitária africana foi introduzida numa sociedade de regime de produção capitalista latifundiário e escravagista, sendo paulatinamente convertida na expressão dos interesses da classe social oprimida e não nos anseios da sociedade global. Bastide evidenciou a capacidade de resistência das camadas populares em relação aos processos de sincretismos católicos por meio do seu apego aos valores mágicos.

Todavia, Bastide refuta os pressupostos do marxismo ao exaltar o candomblé e o espiritismo da umbanda, religiões que obedecem à causalidade econômica do regime capitalista e que contingenciam a situação da classe subalterna. Estas religiões seriam instituintes, ou seja, incidem sobre a realidade por não serem uma mera fantasmagoria ou ideologia. Suscitavam a penetrabilidade do todo sobre as partes, fazendo nascer um ideal aliancista entre as diferentes classes sociais.

O otimismo que Bastide demonstrou ao constatar que a camada subalterna abria mão de seus ideais classistas ao interiorizar os valores cristãos da classe média, convertendo a macumba paulatinamente em umbanda, revela que Bastide, apesar de referendar o referencial marxista em sua análise, preferiu permanecer crítico a ele. $\mathrm{O}$ autor assinalava como positiva a formação de um fato social total, circunstância em que o determinismo das classes sociais se torna latente. Enaltecia o ideal aliancista como condição sine qua non para que houvesse a moralização do capitalismo, tal como concebia a tradição sociológica francesa.

\section{A tradição sociológica francesa e o ideal aliancista}

Durkheim foi o arquiteto e herói fundador da sociologia. Alguns autores sugerem que essa assertiva é válida, sobretudo, quando se toma como referência a França, país onde seu pensamento deixou inúmeros discípulos. Ainda que muitos deles tenham direcionado duras críticas a Durkheim, nota-se que, de um modo geral, a ideia de que a sociedade erige-se como uma força moral coercitiva, exterior e anterior ao indivíduo (Durkheim, 2012), arraigou-se no pensamento social francês. A insistência em associar os fatos sociais à coesão e à solidariedade entre as partes e o todo afastou essa tradição intelectual da 
percepção teórica que reconhece o indivíduo como fundamento da compreensão filosófica do mundo. Ao privilegiar o peso da sociedade sobre o indivíduo, Durkheim acabaria por afirmar a atuação individual como uma contingência. $\mathrm{O}$ indivíduo apenas se manifestaria na medida exata em que obedece ao sentido ditado pelo social. Não à toa, o livre-arbítrio em sua teoria está associado às ideias de anormalidade e de patológico, ou seja, a algo que provoca o rompimento com as formas normais da vida em sociedade (Ortiz, 1989).

Essa percepção está baseada no pressuposto de que, embora o fenômeno social tenha suas raízes na consciência do indivíduo, a vida coletiva não é uma imagem aumentada da vida individual. Isto porque a liberdade individual é sempre e em toda parte limitada pela coerção social, quer sob a forma de hábitos, de costumes, de leis e regulamentos. Daí viria a crença de que, quando postos em sociedade, os homens formariam um novo ser que tem sua natureza e suas leis próprias e que é preponderante em relação à inclinação individual. É o ser social. Durkheim define, então, o fato social como uma força exterior que é geral e que é independente das manifestações individuais. Dessa suposição decorreria a ideia de que a generalidade configura a normalidade dos fenômenos sociais. É por esta razão que, dentre todos os objetos que são concernentes à sociologia, Durkheim elege a moral como a que mais lhe interessava. Ele acreditava que era por meio das ideias e dos sentimentos comuns que se garantia a unidade e a continuidade da vida coletiva (Durkheim, op cit).

Essa opção explica porque Durkheim deixa de lado a abordagem histórica e a análise das estruturas. É que as estruturas seriam extremamente flexíveis e pouco suscetíveis à generalização. Embora houvesse leis da casualidade na história, estas nunca se repetem. É por isso que a sociologia de Durkheim é descritiva e não se ocupa em determinar as causas e condições dos fenômenos sociais. A função social que sua sociologia cumpre é justamente permitir que a sociedade tome consciência de sua unidade orgânica, que o indivíduo reaja contra sua tendência dispersiva, deixando-se penetrar pela massa social. Seria somente assim, abdicando da plena liberdade individual, que o homem se tornaria solidário ao outro. ${ }^{6}$ Por isso, Durkheim se propõe a fazer uma ciência que permita conservar o caráter

6 Durkheim aproxima seu pensamento do de Hobbes quando este supõe que o homem, deixado em seu estado natural, é uma ameaça à vida em sociedade porque faz surgir o estado de guerra (Hobbes, 1979). Para evitar isso, Hobbes reivindica o surgimento de um pacto social no qual todos os homens renunciem o autogoverno em função de uma instância externa. Durkheim, ao contrário, supõe que a vida em sociedade apenas se torna possível por meio da obediência à moral que emana do social. É que o social, deixado em seu livre curso, apaziguaria as veleidades e a vontade humana, tornando possível o surgimento da solidariedade entre homens (Castro; Dias, 1976). 
sagrado da moral, ou seja, o sentimento de obrigação e de disciplina que provém de uma consciência mais elevada, e que ganha um sentido laico pela ciência (Durkheim, 2015). O intelectual faz uma física dos costumes e do direito com o intuito de que os homens não apenas se conformem à regra moral burguesa, mas que a desejem; que abandonem a ideia de perfeição.

Não à toa, Durkheim destaca em sua teoria o papel desempenhado pela divisão do trabalho em sociedades complexas (Durkheim, 1978). A divisão do trabalho faria com que as vontades individuais se movam na direção de fins comuns. De certa maneira, a especialização das funções atuaria do mesmo modo que as representações coletivas em sociedades simples, como uma força que acentua a conformidade moral entre os homens. Porém, se nas sociedades simples a coesão entre os homens é proveniente de uma razão coletiva homogênea e de uma solidariedade mecânica, nas sociedades complexas, cujas crenças coletivas são heterogêneas, seria a divisão do trabalho responsável por imprimir um encadeamento causal entre elas, tornando as diferenças entre os homens integradas ao fazer nascer a solidariedade de tipo orgânica. Deste modo, para além dos serviços econômicos que a divisão de trabalho proporciona, estariam os efeitos morais, como o de criar entre pessoas socialmente desiguais um sentimento de solidariedade.

A divisão do trabalho não produziria uma consciência coletiva comum porque é da natureza das tarefas especiais escapar à ação da consciência coletiva. As funções, quando apresentam generalidade, despertam um sentimento em comum; quando se especializam, fazem os sentimentos se tornarem heterogêneos. Disso decorre que a consciência coletiva não tem nas sociedades complexas uma autoridade difusa. Elas apenas fixam a maneira pela qual as diferentes funções devem se combinar para se tornarem harmônicas. Por esta razão, os sentimentos comuns nem sempre se fazem presentes na consciência individual, o que permite que o indivíduo disponha de maior liberdade em sociedades de solidariedade de tipo orgânica do que em sociedades de solidariedade mecânica, ${ }^{7}$ mesmo que seu grau de autonomia seja limitado.

Deste modo, a solidariedade orgânica, ao impor que os homens se distingam uns dos outros pelas diferentes funções que desempenham, permite que cada um tenha uma esfera própria de ação e personalidade. ${ }^{8}$ Ao mesmo tempo, à medida que as funções se especializam, a coesão social se torna maior, uma

\footnotetext{
7 Nas sociedades de solidariedade mecânicas, o indivíduo não se pertence, é literalmente uma coisa que a sociedade dispõe (Durkheim, 1978).

8 Na solidariedade mecânica, a personalidade individual é absorvida pela personalidade coletiva (Durkheim, op cit).
} 
vez que cada homem depende mais da sociedade para suprir todas as suas necessidades. A atividade de cada um é mais pessoal, embora não seja completamente original, já que, com o exercício da profissão, os homens se conformam às necessidades da corporação capitalista.

Durkheim contraria, então, as análises que acusam a divisão do trabalho de reduzir a condição do indivíduo ao papel de máquina e de gerar o homem alienado ao não permitir que este desenvolva todas as suas potencialidades (Marx, 1978). Contrariamente a Marx, Durkheim supõe que a divisão do trabalho não faz com que o trabalhador fique curvado apenas sobre sua tarefa, uma vez que este possui consciência de que age e sofre reações dos demais colaboradores. Para ele, o indivíduo subalterno não perderia totalmente o controle de sua ação com a divisão do trabalho. ${ }^{9}$

Ao mesmo tempo, Durkheim considera que a progressiva especialização das funções força as pessoas a entrar no mercado para trocar bens e serviços indispensáveis à sua sobrevivência, o que faz com que o ato da troca tenha uma dimensão socializadora. Por estar baseada no ideal de reciprocidade, a divisão do trabalho geraria um contrato bilateral que se enraíza no indivíduo, tornando possível a reprodução das instituições sociais por fazer surgir os princípios de livre consentimento e de contrato justo. Seria por meio dela que as sociedades ditas complexas evitariam os desequilíbrios que acarretam a troca injusta e os conflitos de classe. Daí viria a crença de Durkheim no impacto socializador da relação mercantil fundada pela divisão do trabalho de tipo capitalista, isto é, que está baseada na apropriação privada dos meios de produção (Raud-Mattedi, 2005).. ${ }^{10}$

Vale dizer que o autor considerava a política burguesa a moral mais rica e mais complexa que já se pôde observar. Contudo, diferentemente do que afirma a teoria liberal, Durkheim mostra que o bem-estar coletivo não pode decorrer da busca egoísta dos interesses individuais, já que a interação que decorre daí

9 Durkheim considera que não era necessário, ao trabalhador, ter uma instrução geral que abranja vastas regiões do horizonte social. Se assim fosse, o operário acabaria por achar a especialização intolerável, impedindo aquilo que é o fundamento da solidariedade e da coesão social numa sociedade burguesa, a divisão do trabalho (Durkheim, 1978).

10 Durkheim supõe que a progressiva preponderância da solidariedade orgânica sobre a solidariedade mecânica é uma lei histórica. Mas adverte para o estado de anarquia que se instala na sociedade burguesa quando a esfera econômica não está regulada moralmente e ganha autonomia. Contraria, então, a teoria liberal, ao mostrar que o bem-estar coletivo não pode decorrer da busca egoísta dos interesses individuais. É significativo que a sua noção de anomia venha justamente lamentar as consequências mórbidas da ausência de regras morais na divisão do trabalho. Para Durkheim, apenas nas sociedades em que há observância da moral, ocorre o respeito ao indivíduo. Seria apenas resgatando a moral das reciprocidades nas relações sociais que a sociedade burguesa evitaria a exploração do fraco pelo forte, sobretudo no mercado de trabalho, fazendo valer o respeito ao indivíduo. (Raud-mattedi, op. cit). 
é por demais superficial para originar a coesão social entre os indivíduos. ${ }^{11}$ Por esta razão, o fim último da ciência positiva seria ressaltar a moral que emana da divisão do trabalho e que está baseada na ideia da cooperação ou da reciprocidade entre as partes contratantes. Seria apenas assim que o individualismo das sociedades modernas concorreria para a estabilidade da sociedade capitalista. Por meio da moral que emana da divisão do trabalho, o indivíduo se submeteria à sociedade, sendo esta submissão condição de sua libertação (Durkheim, 2015). ${ }^{12}$ Ao defender a irredutibilidade do ideal moral ao móbil utilitário, Durkheim quis salvaguardar na civilização o que ela trouxe de mais caro ao homem: a necessidade de sair de si e buscar a cooperação (Durkheim, 1996).

Deste modo, na contracorrente do marxismo, que supõe que a de divisão do trabalho na sociedade capitalista gera o homem alienado e separa os indivíduos em classes opostas, Durkheim enxerga a divisão do trabalho como o processo que gera a solidariedade entre indivíduos hierarquicamente desiguais e liberta o homem do julgo de uma consciência coletiva absolutamente homogeneizante.

Vale lembrar que a solidariedade de tipo mecânica foi considerada por Durkheim como típica de sociedades inferiores. Durkheim chamou de horda o agregado assim caracterizado. É com esta opinião que considerou o comunismo como o produto necessário desta coesão especial que absorve o indivíduo dentro do grupo, a parte no todo. Afinal, onde a propriedade é coletiva, a personalidade não pode deixar de ser única. A personalidade só pode se tornar individual quando o indivíduo, desligando-se da massa, torna-se ele também um ser pessoal e distinto, não apenas enquanto organismo, mas como elemento da vida social. Isso apenas ocorre quando a sociedade tem como fundamento a propriedade privada. Deste modo, Durkheim rompe, sobretudo, com a interpretação marxista que concebe que a liberdade humana apenas se alcança com a supressão da propriedade privada. Para Marx seria apenas nessa circunstância que o homem encontra possibilidade de desenvolver todas as suas faculdades. Significativamente, a liberdade individual irrestrita foi considerada por Durkheim como uma questão puramente metafísica. ${ }^{13}$

\footnotetext{
11 Durkheim contraria os economistas por eles conceberem um indivíduo geral e abstrato que se motiva por valores estritamente egoístas, racionais e individuais (Castro; Dias, op cit).

12 Para Durkheim, a necessidade imperiosa da cooperação entre indivíduos hierarquicamente desiguais é a alma de toda religião.

13 "Mesmo que as crenças e as práticas sociais nos penetrem desde fora, isto não quer dizer que nós as recebemos passivamente, sem submetê-las a modificações. Ao pensar as instituições coletivas, ao assimilá-las a nós, nós as individualizamos, nós lhes damos mais ou menos nossa marca pessoal; é assim que, pensando o mundo sensível, cada um de nós o apresenta à sua maneira, e que os sujeitos diferentes se adaptam diferentemente a um mesmo meio físico. É por isso que cada um de nós faz, em certa medida,
} 
É que a sociedade, para Durkheim, não emana do indivíduo. Sua máxima é que o todo não é idêntico ao somatório das partes. A sociedade traduz a mentalidade dos grupos e não a mentalidade dos indivíduos. Por isso, para se entender a sociedade não se deve partir das representações individuais, mas das representações coletivas. Disso decorre outro pressuposto não menos importante: a consciência coletiva é algo mais que um simples epifenômeno da morfologia social, do mesmo modo que a consciência individual é algo mais que uma simples eflorescência do sistema nervoso. A sua ideia é a de que, do mesmo modo que se deve evitar uma concepção epifenomista que explica a concatenação das ideias no homem por causas puramente físico-químicas, deve-se evitar também "a sociologia individualista" que não faz senão aplicar à vida social o princípio da velha metafísica materialista que explica o todo pela parte. Para Durkheim, à medida que a associação se constitui, ela dá origem a fenômenos que não derivam diretamente da natureza dos elementos associados. Há uma certa independência do todo em relação às partes, das representações coletivas em relação às representações individuais. Isto é, a consciência coletiva não necessariamente traduz os fatos da morfologia social, muito embora os tenha como seu substrato. As representações coletivas são realidades parcialmente autônomas que não se ligam à esta ou àquela característica da morfologia social (Durkheim, 2015). É que as estruturas sociais, por serem demais flexíveis e dinâmicas, tornam-se um fenômeno secundário e de difícil acesso. Sua máxima é que as instituições humanas não surgem por decreto, elas cumprem uma função, satisfazem uma necessidade da vida social. Daí ele considerar um erro as teorias revolucionárias que consideram a moral social uma legislação sempre revogável. ${ }^{14}$

Com Durkheim, a ideia de liberdade individual como algo que se alcança apenas quando o todo prepondera sobre as partes se arraigou na sociologia francesa. Pode-se dizer que esta tradição intelectual associou os fatos sociais à solidariedade que nasce entre indivíduos desiguais, ao ideal aliancista que une as classes sociais opostas por considerar como metafísica a liberdade individual que nasce quando se abole as diferenças sócio-estruturais entre os indivíduos.

sua moral, sua religião, sua técnica. Não há conformismo social que não comporte toda uma gama de nuances individuais. No entanto, o campo de variações permitidas é limitado. Ele é nulo ou muito frágil no círculo dos fenômenos religiosos e morais em que a variação se torna facilmente um crime; ele é muito amplo para tudo o que concerne à vida econômica. Mais cedo ou mais tarde, mesmo nesse último caso, encontra-se um limite que não pode ser superado" (Durkheim, 2012).

14 O próprio autor reconhece que essa orientação imprime um caráter sabidamente conservador à sua teoria (Castro; Dias, op cit). 
Mesmo autores como Marcel Mauss e Maurice Halbwachs, que estiveram interessados na realidade interior do indivíduo, conceberam-no como totalmente dominado pela razão coletiva e desconsideraram a possibilidade de uma interferência dos fatores propriamente individuais na realidade. Para eles, as diferenciações sócio-estruturais existentes entre indivíduos e grupos eram anuladas frente ao poder apaziguador das representações coletivas. Ao suporem uma introjeção das representações coletivas nas consciências individuais, Mauss e Halbwachs anularam a importância do indivíduo como ser único ou o papel das diversificações estruturais como modificadores dos processos sociais, como fizera a sociologia durkheimiana.

Marcel Mauss, por exemplo, ainda que reconhecesse a pertinência dos estudos de psicologia, acreditava que o fato social é sempre interiorizado pelas consciências individuais, o que fazia do inconsciente individual sempre um inconsciente coletivo. Somente na aparência cada indivíduo constituía uma unidade específica, diversa das demais, afinal, no seu inconsciente os domínios do "eu" e do "outro" se confundem. Sendo assim, Mauss pontua que os fenômenos sociais tinham ainda outra dimensão não percebida por Durkheim, a dimensão inconsciente. Por isso, era preciso penetrar na subjetividade a fim de descobrir nas profundezas do inconsciente as formas de atividade mental comuns aos homens de uma mesma sociedade. Ao pontuar isso, Mauss, diferentemente de Durkheim, não privilegiou a razão em detrimento da afetividade; pelo contrário, concebeu que existia uma reciprocidade entre ambas (Queiroz, 1983).

A ideia da reciprocidade entre inconsciente individual e fato social é constatada por Mauss a partir do estudo de sociedades primitivas. O intelectual observa que nestas sociedades em que a dádiva configurar-se como um fato social total, o ideal de reciprocidade permeia a relação entre o indivíduo e sociedade, sendo inclusive o princípio norteador de toda troca. A moral da dádiva imporia a necessidade da contraprestação, inclusive nas relações econômicas, sendo esta a origem do contrato e da troca nas sociedades primitivas. Mauss comprova desta maneira que as sociedades primitivas não eram privadas de mercado. E mais: notou que havia nelas o princípio de contraprestação, princípio exaltado por Durkheim como a base da moral contratual das sociedades complexas. E, assim, Mauss pôde se abrir às sociedades não-ocidentais, reconhecendo nelas a existência de um ideal de reciprocidade que não era contraposto à racionalidade burguesa.

O importante a reter é que, ao fazer este adendo à interpretação durkheimiana, Mauss insistirá continuamente na imbricação entre utilitário e simbólico, entre interesse e desinteresse. Isso permitirá que ele refute a tese durkheimiana 
da oposição radical entre sociológico e psicológico. Entre o social e o individual não haveria mais ruptura, mas gradação e tradução recíproca, já que os simbolismos constitutivos de um plano são passíveis de tradução no outro. É por esta razão que os fatos sociais passam a ser considerados como fatos simbólicos totais. Passam a faltar neles aquilo que, segundo Durkheim, garantia a sua objetividade: a coerção. Não que ela desapareça. É que a obrigação deixa de ser exercida como uma exterioridade por haver entre indivíduo e sociedade não um hiato, mas uma relação de cotradução. Disso decorre que, mesmo em sociedades tradicionais, o indivíduo não é totalmente livre, já que a liberdade consistiria justamente na espontaneidade da obrigação. $\mathrm{O}$ indivíduo afirmaria como moralmente desejável exatamente aquilo o que a coletividade afirma como tal. Daí 0 autor, com a descoberta da dádiva conceber a obrigação e a liberdade, 0 interesse e o desinteresse como irredutíveis.

Assim como Durkheim, Mauss considerou que nenhuma sociedade humana pode edificar-se exclusivamente sobre o registro do contrato utilitário, sendo, por isso, indispensável à qualquer ordem social a solidariedade. Afinal, o altruísmo não pode nascer do egoísmo. Porém, contrariamente a seu mestre, que acreditava que tal conjugação entre interesse e solidariedade provinha da maior divisão do trabalho, Mauss supunha que tal conjugação apenas pode surgir da subordinação dos interesses materiais a uma regra simbólica que os transcendam, como a da dádiva. É que mesmo sendo socialmente imposta, a dádiva só adquire sentido numa certa atmosfera de espontaneidade. Mauss sugere que mesmo a sociedade selvagem mais controlada pela obrigação ritual deixa um espaço para a iniciativa pessoal. Submetendo-se à lei dos símbolos que criam e fazem circular os produtos, os homens simultaneamente produziriam sua individualidade no dar para receber.

Se situa, então, Mauss entre o individualismo do liberalismo econômico e político, que deixa ao livre jogo do mercado a organização da maior parte da existência social, e o desejo de que o Estado seja mais atuante na vida social. Para o intelectual, a sociedade é sempre irredutível ao mercado. Daí a desavença do intelectual também em relação ao marxismo, que acreditava na possibilidade de uma sociedade sem mercado (Caillé, 1998).

Para Mauss, a moral contratual da dádiva não é contrária à moral contratual das sociedades complexas. Pelo contrário, a dádiva se faz presente todas as vezes em que o ideal de lucratividade da troca não suprime a noção de interesse pessoal. E mais: o ideal da reciprocidade se faz presente também no direito moderno quando as classes sociais se relacionam pelo ideal caridade e não apenas por meio da noção de interesse. Seria justamente a insurgência da 
dádiva nas relações de troca que permitiria a supressão de um patronato inconsciente e injurioso, apaziguando as injustiças e os conflitos entre as classes de tal modo a fazer do regime capitalista um sistema mais humano. Mauss irá reivindicar o resgate da moral da dádiva para que se restitua a solidariedade entre os indivíduos e grupos hierarquicamente desiguais nas sociedades complexas. O sistema simbólico da dádiva neutralizaria os conflitos de classe, mas sem se chocar com o ideal do lucro, contribuindo para estabilização do sistema capitalista (Mauss, 2013).

Mauss identifica por meio da dádiva, então, a presença de um valor sentimental nas coisas além do seu valor venal..$^{15}$ Todavia, conclui que estes valores sentimentais não representam os valores de totalidade nas subjetividades individuais; expressam, na realidade, os valores da coletividade. ${ }^{16}$ Afinal, por meio deles, os homens se obrigam mutuamente na expectativa de dar para receber. Isso comprovaria que a dádiva não se pauta em valores de uso, nem tampouco é o princípio por meio do qual o proletariado será conduzido à desalienação, como supôs o marxismo. ${ }^{17}$ Pelo contrário, Mauss vê na dádiva uma possibilidade de que patrões e empregados possam colaborar entre si, consolidando o que ele chamou de socialismo de Estado. $\mathrm{O}$ ideal de que haja reciprocidade nas relações de troca faria com que os patrões contribuam para a seguridade de seus funcionários, fornecendo-lhes garantia contra o desemprego, a doença, a velhice, garantindo-lhes as caixas de assistência familiar. Ao impor a obrigação de dar e retribuir, a dádiva seria uma ideologia próxima da generosidade ao impedir alienação total do indivíduo nas relações de troca. Permitiria a superação da dualidade existente no pensamento ocidental entre solidariedade e egoísmo, ao viabilizar uma crítica ao individualismo da sociedade burguesa, sem, no entanto, suscitar o rompimento com a lógica do lucro. Tal como Durkheim,

15 A retribuição da dádiva seria explicada pela existência de uma força dentro da coisa dada, um vínculo de almas que está associado de maneira inalienável ao nome do doador, ou seja, ao seu prestígio. A este vínculo espiritual cuja expressão simbólica está ligada à ação ou transação, Mauss dará o nome polinésio de mana (Sabourin, 2007). "Se coisas são dadas e retribuídas, é porque se dão e se retribuem "respeitos" podemos dizer, igualmente, "cortesias". Mas é também porque as pessoas se dão ao dar, e, se as pessoas se dão, é porque se "devem" - elas e seus bens - aos outros (Mauss, 2003, p. 263). Pois bem, a noção de mana supõe uma preocupação pelo outro, decorrendo daí o ideal de que haja reciprocidade na troca. Todavia, trata-se de uma relação de interesses, mas que supõe uma reciprocidade mínima.

Nota-se que é a partir de Mauss que o esforço de Durkheim de distinguir a coletividade da totalidade se torna mais proeminente. Com isso, Mauss reforça a ideia durkheimiana de que as desigualdades sócio-estruturais entre os indivíduos são apaziguadas quando emerge uma moral social comum entre as classes sociais.

17 Mauss faz da noção de reciprocidade um privilégio do indivíduo saído da infância ou da sociedade já civilizada. Por esta razão, a reciprocidade não quer dizer sempre igualdade. Na dádiva haveria reciprocidade, mas não igualdade. (Mauss, 1971) 
Mauss acreditava que era por meio de uma aliança entre as classes sociais que um homem não totalmente alienado surgiria, usufruindo ainda de um grau de liberdade individual (Lanna, 2000).

Contemporâneo de Mauss, Maurice Halbwachs também foi atraído pela psicologia social e, assim como ele, preocupou-se em determinar o grau de liberdade que os indivíduos possuíam frente à moral social burguesa. Sua perspectiva mais próxima da esfera individual o levou a perceber que a inserção dos indivíduos em determinada camada socioprofissional condicionava-lhes as suas mentalidades. Isso o fez inserir a noção de classe social em sua análise, o que constituía grande novidade, pois, até então, a sociologia francesa havia se mantido alheia à essa interpretação. Todavia, apesar de ter notado que a mentalidade dos indivíduos variava conforme a posição social que ocupavam, Halbwachs permaneceu preso aos axiomas da escola durkheimiana ao supor que a coletividade social prevalece sobre o individual (Halbwachs, 1950).

É que Halbwachs estudou a relação entre indivíduo e sociedade por meio da categoria de memória coletiva. Fez esta escolha por considerar que o indivíduo, ao recordar, faz sua memória estabelecer pontos em comum com a memória coletiva. Isso o levou a supor que o indivíduo apenas se lembra porque adota o ponto de vista das representações coletivas. Halbwachs nega, então, que as memórias se ligam de acordo com a consciência individual. A consciência individual não seria responsável por estabelecer a coesão entre as lembranças justamente porque o indivíduo sofre o tempo todo interferência das representações coletivas, mesmo que não as sinta. Para Halbwachs, as diferentes correntes coletivas se articulam no indivíduo por meio de uma associação que se forma fora dele. Disso decorre a sua importante conclusão de que a divisão existente entre os grupos não obedece a um tempo interno ou à posição socioeconômica que o indivíduo ocupa na sociedade, mas às divisões que a percepção coletiva introduz. E se isso revela um ponto de ruptura, revela também um importante ponto de ligação entre as partes e o todo. E foi assim que Halbwachs chamou atenção para o fato de que mesmo as mentalidades condicionadas pelas posições socioeconômicas obedecem às divisões impostas pela consciência coletiva. (Halbwachs, 2003).

A influência Durkheim em seu pensamento se faz notar, então, quando Halbwachs supõe que as representações coletivas estabelecem a unidade entre as memórias e os pensamentos. A consequência disso seria a infiltração das correntes de pensamento coletivo no indivíduo e uma disciplina social que não se interrompe.

Deste modo, apesar de Halbwachs inserir a noção de classe social em sua análise, ele afirma que a memória individual sem sempre reflete da posição social 
ocupada pelo indivíduo ou de um grupo. Isso acontece porque é o pensamento coletivo que define a percepção que os indivíduos possuem das divisões entre os grupos. Assim como Durkheim, ele percebe uma penetrabilidade das representações coletivas no indivíduo. Isso o faz supor que a classe social, embora exista, se faz atuante apenas em momentos ocasionais. Ela apenas se manifesta quando os indivíduos se apoiam não na memória coletiva, mas na memória histórica. Esta desempenharia um papel secundário justamente porque pressupõe uma memória individual preliminar, autônoma. Segundo Halbwachs, não existiu e jamais existirá um panorama histórico que seja absolutamente constituído por memórias individuais independentes. Disso decorre que a história apenas começa quando se decompõe a memória social que retém as continuidades e apaga as rupturas das linhas de evolução. É que na memória coletiva não há linhas de separação claramente traçadas, apenas limites irregulares e incertos, ao passo que na memória histórica o que se tem são as rupturas, as mudanças e as descontinuidades. Por isso, a dificuldade de formação da consciência de classe.

Halbwachs, tal como Durkheim, enxerga como positiva a interpenetração entre memória individual e memória coletiva. Vale lembrar que, para ele, as crises do capitalismo resultam da separação da produção e de consumo em duas zonas distintas. $\mathrm{O}$ problema da sociedade moderna viria justamente do fato de se conceder maior importância à moral do produtor do que à moral do consumidor, daí a recorrente abundância de produtos. Para resolução das constantes crises, seria necessário seguir a moral do consumidor e encontrar as possibilidades do homem se realizar dentro do marco capitalista. Tal se daria por meio de uma vida mais coletiva e não pela emergência da consciência de classe. É que, apesar de na sociedade capitalista haver tal divisão entre produtores e consumidores, haveria condições de surgir, no seio desse regime, pela interpenetração da consciência coletiva na consciência individual, formas de associações e instituições comprometidas com o espírito comunitário que passam por cima desse antagonismo. Assim se instauraria uma moral de colaboração ou de ajuda-mútua que se molda dentro dos marcos do capitalismo e torna possível a conciliação do progresso econômico com uma melhor repartição das riquezas, de tal modo que se eleve o nível das classes inferiores.

Deste modo, Mauss, assim como Durkheim, preconizou que não se fizesse referência às diferenças sócio-estruturais entre os indivíduos e que se abdicasse da ideia de uma liberdade individual total para que se formasse uma moral da reciprocidade entre os diferentes grupos sociais e a sociedade capitalista pudesse se estabilizar.

Georges Gurvicth, embora não seja francês, por intermédio da noção de fato social total de Marcel Mauss, também foi profundamente influenciado pela 
escola durkheimiana. Por meio desta noção, o teórico se manteve crítico ao marxismo ao apreender a totalidade social sem se ater ao determinismo que provém das estruturas ou das classes sociais. Essa metodologia o fez herdar da sociologia francesa o mote teórico que discute a relação indivíduo e sociedade por meio de princípios organizacionais e não por meio de princípios estruturais. Não que não haja em Gurvitch menção à noção de estrutura, mas ele a redefine quando considera que as classes sociais podem ser, assim como a totalidade social, instâncias organizacionais (Gurvitch, 1973). Isto é, elas tanto podem se orientar pelo lugar ocupado pelo indivíduo no sistema produtivo como pelos valores culturais da coletividade. Foi desta maneira que Gurvitch explicou o fato da estrutura sofrer constantemente processos de desestruturação e estruturação (Gurvitch, 1971).

Gurvitch supõe que quando as representações culturais determinam o modo de agir de uma classe social, ocorrem os momentos de desestruturação, isto é, as representações culturais deixando de ser simples epifenômenos dos fatos da estrutura para repercutirem na realidade. Seria justamente nessas circunstâncias que o indivíduo gozaria de maior autonomia pelo fato dos conflitos entre as classes se apaziguarem (Gurvitch, 1968).

Assim como os demais autores, o intelectual via virtualidades positivas quando ocorre a permeabilidade das representações coletivas no indivíduo ou, para fazer jus aos termos usados por Gurvitch, aos momentos de desestruturação que fazem as classes sociais se pautam em princípios organizacionais. Seria nestas situações nas quais os indivíduos deixam de lado a sua situação de classe para se pautar pelos valores organizacionais que haveria maior liberdade individual (Gurvitch, op. cit). É que os determinismos de classe, por serem demasiadamente estruturantes, aumentariam a contingência ao fazer a razão humana um simples epifenômeno das estruturas. Por isso, ele defende que ocorra uma deflação das antinomias, isto é dos determinismos das classes para que se forme um determinismo sociológico (Gurvitch, 1987) no qual os determinismos astrutural e global, isto é, os determinismos ligados à escala da sociabilidade individual e do conjunto, se manifestem.

É por valorizar o determinismo sociológico que o termo estrutura em Gurvitch aproxima-se do conceito de fenômeno social total de Marcel Mauss ${ }^{18}$. Para este autor, a estrutura, embora sofra um movimento de estruturação, se desestrutura quando se forma o determinismo sociológico, no qual as escalas do eu

18 Gurvitch supõe que o fenômeno social total apenas é total na medida em que reflete a ordenação da coletividade, isto é, os determinismos estruturais, ligado à sociabilidade individual, e o global (Queiroz, 1983). 
e do nós se pronunciam. Seria nesta circunstância que as ideias deixam de ser simples epifenômenos dos determinismos das classes que a racionalidade humana é concretizada em ato, permitindo maior liberdade individual. Em outros termos: as ideias passam a ter incidência sobre a realidade. Deste modo na contracorrente do marxismo, Gurvitch quer que se atenue os determinismos que provém das infraestruturas (Gurvitch, 1968).

Localizando esta circunstância na história, o autor a identifica ao capitalismo liberal, momento no qual todas as classes formam sua consciência de acordo com o desenvolvimento alcançado pelas forças produtivas. Neste momento histórico, as forças produtivas, além de alicerçarem a vida material dos homens, também fazem as classes sociais se pautarem por fatores organizacionais. As forças produtivas promovem, então, uma desestruturação ao instalar entre as três instâncias do real (as escalas do eu, das classes e do nós) uma dialética de complementaridade que suspende a contradição entre as classes sociais. Seria nesta circunstância que as ideias deixam de ser um fenômeno secundário para repercutir na realidade, formando um fato social total.

A desavença de Gurvitch com o marxismo viria por esta teoria considerar que a racionalidade humana torna-se menos contingente por meio do aumento do determinismo das classes. É que a liberdade individual que Gurvitch almeja não é metafísica, material e irrestrita, como pressupõe o marxismo que subordina a criação humana ao aumento do determinismo das classes para que o homem goze de todas as suas potencialidades e se torne total. Gurvitch considera que o determinismo das infraestruturas, por ser demasiado rígido, faz a liberdade humana ser tão livre que a torna irreal e impotente. Por esta razão, as ideias humanas se tornam simples epifenômenos das infraestruturas, não tendo incidência sobre a realidade. Daí ele defender que as classes sociais devam se pautar não pela sua consciência de classe, mas pela consciência que se forma de acordo com o desenvolvimento alcançado pelas forças produtivas. Entretanto, o próprio autor reconhece que liberdade que se alcança por meio desta consciência que ele chama de real é uma liberdade limitada porque se situa entre a contrarrevolução e a revolução permanente.

E, assim, Gurvitch, em vez de diminuir a contingência da razão humana a aumenta por fazer a liberdade individual estar condicionada à adoção dos preceitos burgueses. Assim como fizera a tradição durkheimiana, o intelectual condicionou a liberdade individual ao livre curso do social, à uma dialética da evolução na qual a atuação das partes é subordinada à força integrativa do todo porque faz os desequilíbrios existentes entre as várias escalas do real (a escala do eu, das classes e dos outros) se tornarem complementares. O fato social total 
ou o determinismo sociológico que advém daí, por não traduzir os rigores dos determinismos das classes e das desordens libertárias, gera uma ordem social na qual a consciência dos homens passa a ser uma elaboração mais psicológica do que classista. Afinal, a consciência individual torna-se uma elaboração discursiva e empiricista, não é decorrente da compreensão de uma situação das classe ou reflexo do desejo que sejam eliminadas as diferenças socioestruturais entre os indivíduos. Daí a instalação de uma dialética de complementaridade que consolida o que há de consensual entre as três escalas do real e promove a deflação dos determinismos das classes. Gurvitch utiliza novos termos para defender, assim como fizera a tradição sociológica francesa, um ideal aliancista que promove uma liberdade individual restrita que é reflexo da supressão dos determinismos das classes sociais, apesar dele reverenciar, na contracorrente de Durkheim, o capitalismo liberal. ${ }^{19}$

\section{Considerações finais}

Sendo assim, chama atenção para o fato de Bastide ter permanecido preso à escola sociológica durkheimiana, apesar de direcionar críticas ao organicismo inerente à essa tradição intelectual. Mesmo quando procurou romper com este ideal, fazendo referência a Georges Gurvitch, reafirma em novos termos a ideia de que era necessário a interferência do todo sobre as partes, ao sustentar a ideia de um pacto que seria decorrência da anulação da antinomia entre as classes sociais. E, assim, revela uma noção de sagrado que é instituinte, ou seja, que consolida a ordem social burguesa, e não um sagrado selvagem que promove uma autonomia das partes em relação ao todo ou uma antinomia entre as classes sociais. Assim como Durkheim, acaba por considerar a liberdade individual plena como fonte da desordem e do irracional.

Afinal, Bastide via com otimismo o fato do sagrado selvagem da macumba estar sendo moldado ou domesticado pelos quadros institucionais da sociedade brasileira, de tal modo a perder o seu caráter explosivo, contrário à ordem social. O sagrado selvagem estava sendo submetido ao controle da coletividade e às razões da ordem. Para ele, as religiões africanas estavam sendo "ressignificadas" pela sociedade e utilizadas em seu proveito.Como Durkheim, Bastide acaba por concluir que a religião, assim como a sociedade, concorrem para

19 Não deixa de ser curioso notar que embora Durkheim faça críticas ao capitalismo liberal e Gurvitch o defenda, ambos almejam uma liberdade individual restrita que provém de uma complementaridade dialética entre as classes sociais, enaltecendo um mesmo ponto de chegada: a aliança entre as classes sociais e a ordem social burguesa. 
transformar o espontâneo em institucional. Significativamente, o sagrado selvagem não modelado pelo social foi tido por Bastide como decorrência de uma sociedade anômica. ${ }^{20}$

Comprovava o autor, por meio da noção de fato social total gurvitchiano, que o cristianismo já tivera um efeito transformador da mentalidade africana. ${ }^{21}$ $\mathrm{O}$ transe não seria mais um modo de sair da sociedade, não seria um contraponto da ordem social, uma catarse ou um ato revolucionário; pelo contrário, ele seria um discurso aceito pela ortodoxia para que se evite ações desmedidas. $\mathrm{O}$ transe não romperia com o instituído, seria quando muito uma descontinuidade continuada, revelando que a crise do instituído que não acarreta a crise do instituinte, isto é, da razão, da ciência, do progresso, portanto. Pelo contrário, Bastide afirmou que a lógica do ut des africana, ao ser domesticada pelo social, suscitava uma aliança interclasse tornando-se uma religião tal como concebeu a sociologia francesa. Bastide revelava, então, nas suas obras de maturidade, uma reconciliação com a tradição que se manteve presa às manifestações da ordem e das regularidades. ${ }^{22}$

Como autor eclético que foi, resta sempre a dúvida: queria Bastide uma traição ou uma tradução ao sagrado? Importa assinalar que o autor referendou um sagrado que é instituinte, ou seja, que reproduz as lógica da sociedade burguesa ao não manifestar o desejo de uma nova ordem. Por esta razão, não queria Bastide que as crenças africanas traduzissem o sagrado selvagem, mas que fizessem uma traição a ele.

\section{Referências}

BASTIDE, R. Brasil: terra de contrastes. São Paulo: DIFEL, 1979.

Les religions africaines au Brésil. Vers une sociologie des interpénétrations de civilisations. Paris: Press Universitaires de France, 1960.

As Américas negras: as religiões africanas no novo mundo. São Paulo: Difusão Européia do Livro, Editora da universidade de São Paulo, 1974.

20 Não à toa, a macumba, religião em que o indivíduo se arroga um papel maior, foi considerada como seita mágica, isto é, como uma negação do sagrado ou como uma expressão do sagrado selvagem que não foi institucionalizado. Esta seria uma seita catártica que expressa tensões não domesticadas pela religião. Significativamente na macumba, Exu, o Deus intermediário, é transformado em anjo da rebeldia (Bastide, 2006).

21 O sentimento de vergonha peculiar ao pensamento africano seria similar ao de culpa cristão (Bastide, 2006).

22 Bastide afirma o sagrado selvagem como um bricabraque de velhas tradições religiosas, por isso, ele apenas produziria instantes de insurreição. 
. Problemas afro-brasileiros. In: Roger Bastide: ensaios e pesquisas /Maria Isaura Pereira de Queiroz, org. Textos. CERU/USP, São Paulo, Série 2 ; n. 5, p.-,1994.

. O sagrado selvagem e outros ensaios. São Paulo: Companhia das Letras, 2006. . Introdução ao estudo do termo "estrutura”. In: Usos e sentidos do Têrmo “estrutura”. Roger Bastide (org). São Paulo: Editora Herder, 1971.

CAILLÉ, A. Nem holismo nem individualismo metodológicos: Marcel Mauss e o paradigma da dádiva. Rev. bras. Ci. Soc., São Paulo, v. 13, n. 38, p. 5-38, Oct. 1998.

CASTRO, A. M. de; DIAS, E. F. Introdução ao pensamento sociológico. Rio de Janeiro: Eldorado Tijuca, 1976.

DURKHEIM, É. As formas elementares da vida religiosa. O sistema totêmico na Austrália. São Paulo: Martins Fontes, 1996.

. Sociologia e filosofia. São Paulo: Ed EDIPRO, 2015.

As regras do método sociológico. São Paulo: Ed EDIPRO, 2012.

. Emile Durkheim: Sociologia. José Albertino Rodrigues (org). São Paulo, Ática, 1978.

GURVITCH, G. "As 'estruturas' em sociologia”. In: Usos e sentidos do têrmo “estrutura”. Roger Bastide (org). São Paulo: Editôra Herder, 1971.

Dialética e Sociologia. São Paulo: Vértice, Editora Revista dos Tribunais, 1987. El concepto de clases sociales de Marx a nuestros días. Argentina: Ediciones Nueva Visíon, 1973.

Determinismos sociais e liberdade humana [1955]. Rio de Janeiro, São Paulo: Forense, 1968.

HALBWACHS, M. Morfologia social (história e sociedade). Portugal: Edições 70, 2010. A memória coletiva. São Paulo: Centauro, 2003.

. Las clases sociales. México/ Buenos Aires: Fondo de Cultura Económica, 1950. HOBBES, T. Leviatã ou Matéria, forma e poder de um estado eclesiástico e civil. São Paulo: Abril Cultural, 1979.

LANNA, M. Nota sobre Marcel Mauss e o ensaio sobre a dádiva. Curitiba: Revista Sociologia Política, n. 14, p. 173-194, jun. de 2000.

MARX, K. Manuscritos econômicos-filosóficos e outros ensaios recolhidos. São Paulo: Ed Abril Cultural, 1978.

MAUSS, M. 0 ensaio sobre a dádiva. Forma e razão da troca nas sociedades arcaicas.

São Paulo: Cosac Naify, 2013. Antropologia e sociologia. São Paulo: Cosac \& Naif, 2003. . Ensaios de sociologia. Essais de Sociologie. Paris, Seuil, 1971.

ORTIZ, R. A consciência fragmentada. Rio de Janeiro: Paz e Terra, 1980.

. Durkheim: arquiteto e herói fundador. Revista Brasileira de Ciências Sociais, vol. 4, n.11, São Paulo, outubro de 1989. 
PEIXOTO, F. A. P. Diálogos brasileiros. Uma análise da obra de Roger Bastide. São Paulo, Editora da Universidade de São Paulo, 2000.

QUEIROZ, M. I. P. de. "Para atingir o imaginário em sociologia. A contribuição de Roger Bastide”. In: O imaginário em terra conquistada/ Maria Isaura Pereira de Queiroz (org). Textos. CERU/USP. São Paulo, Série 2, n. 4, p. 144, 1993.

. O imaginário será mesmo "imaginário"? In: O imaginário em terra conquistada. Maria Isaura Pereira de Queiroz (org). Textos. CERU/USP. São Paulo, Série 2, n. 4, p. 144, 1993.

. (org). "A nostalgia do outro e do alhures: a obra sociológica de Roger Bastide". In: Roger Bastide: sociologia. São Paulo: Ática, 1983.

RAUD-MATTEDI, C. A construção social do mercado em Durkheim e Weber: análise do papel das instituições na sociologia econômica clássica. Revista Brasileira de Ciências Sociais, Vol. 20 n. 57, fevereiro de 2005. Disponível em: <http://www. scielo.br/pdf/rbcsoc/v20n57/a08v2057.pdf >. Acesso em: 03 abr. 2018.

SAUBORIN, E. Marcel Mauss: da dádiva à questão da reciprocidade. Rev. bras. Ci. Soc. [online]. 2008, vol. 23, n. 66, pp. 131-138. ISSN: 1806-9053. Disponível em: $<$ http://dx.doi.org/10.1590/So102-69092008000100008>. Acesso em: 03 abr. 2018.

Recebido em 31/01/2016

Aprovado em 13/12/2017

\section{Como citar este artigo:}

VASCONCELLOS, Dora Vianna. Roger Bastide e a sociologia francesa: traição ou tradução do sagrado? Contemporânea - Revista de Sociologia da UFSCar, v. 8, n. 1, jan.- jun. 2018, pp. 215-238. 